\title{
Qualidade do carvão vegetal submetido a diferentes taxas de resfriamento com trocador de calor
}

\author{
Quality of charcoal submitted to different cooling rates with heat exchanger
}

\author{
Arthur Freitas Gomes ${ }^{\mathrm{I}}$, Marcio Arêdes Martins ${ }^{\mathrm{II}}$, \\ Emanuele G. Pereira' ${ }^{\mathrm{III}}$, Ivanildo da Silva dos Santos ${ }^{\mathrm{IV}}$, \\ Angélica de Cássia Oliveira Carneirov
}

\begin{abstract}
Resumo
O carvão vegetal é um importante insumo na siderurgia nacional e seu uso tem muitas vantagens sobre o carvão mineral e o coque, uma vez que é renovável, menos poluente e com baixos teores de enxofre e fósforo. A partir disso, o objetivo deste trabalho foi avaliar o desempenho do resfriamento artificial do carvão vegetal em forno retangular. Para isso, foi avaliada a influência da variação da velocidade do escoamento de gás pelo leito poroso de carvão na qualidade final do produto. Foram utilizadas quatro velocidades de escoamento, em 3 repetições, totalizando 12 ensaios de carbonizações da madeira em um forno retangular. O uso do trocador de calor proporcionou redução no tempo de resfriamento de 76 para 28 horas. A maior redução no tempo de resfriamento foi obtida com a menor velocidade de escoamento. Nas maiores velocidades ocorreu queima de uma parte do carvão na seção de saída dos gases do forno, o que provocou aumento no tempo de resfriamento. No entanto, verificou-se que essas queimas parciais não causaram diferença significativa no rendimento gravimétrico em relação à testemunha. Para as velocidades adotadas, verificou-se que não houve diferença significativa entre os tratamentos e a testemunha nos parâmetros de qualidade do carvão. Portanto, no dimensionamento de trocadores de calor, deve-se considerar a diferença de pressão entre as aberturas de sucção e injeção dos gases no forno para minimizar a infiltração de ar no forno.
\end{abstract}

Palavras-chave: Resfriamento artificial; Escoamento em meios porosos; Siderurgia a carvão vegetal

\begin{abstract}
Charcoal is an important material in the national steelmaking industry and its use has many benefits over coal and coke, since it is renewable, less polluting and with lower contents of sulfur and phosphorus. The aim of this study was to evaluate the performance of the artificial cooling of the charcoal in a rectangular kiln. It was evaluated the influence of the variation of the velocity of the gas flow through the porous bed of charcoal in the final quality of the product. Four flow velocities were used, in three repetitions, totalizing 12 carbonization tests in a rectangular kiln. The used of heat exchanger provided a reduction from 76 to 28 hours in the cooling time. The highest reduction in cooling time was obtained with lower flow velocity. It was observed that, at higher velocities, part of the charcoal closed to the exhaust section of the kiln was burned, which resulted in an increase in the cooling time. However, these partial burns did not cause the significant difference in gravimetric yield in relation to the control. For the velocities adopted, it was verified that there was no significant difference between the treatments and the control in the quality parameters of the charcoal. Therefore, for the dimensioning of heat exchangers, the pressure difference between the suction openings and the gas injection should be considered to minimize the infiltration of air into the kiln.

Keywords: Artificial cooling; Fluid flow in porous media; Charcoal steelmaking

Engenheiro Agrícola, Graduado em Engenharia Agrícola e Ambiental, Departamento de Engenharia Agrícola, Universidade Federal de Viçosa, Av. PH Rolfs, s/n, Centro, CEP 36570-900, Viçosa (MG), Brasil. arthur.f.eaa@gmail.com (ORCID: 0000-0001-7166-9818)

Engenheiro Químico, Dr., Professor do Programa de Pós-Graduação em Engenharia Agrícola, Departamento de Engenharia Agrícola, Universidade Federal de Viçosa, Av. PH Rolfs, s/n, Centro, CEP 36570-900, Viçosa (MG), Brasil. aredes@ufv.br (ORCID: 0000-0001-5705-9431)

III Engenheira Agrícola, Dra., Pós-Doutoranda do Laboratório de Biocombustíveis, Departamento de Engenharia Agrícola, Universidade Federal de Viçosa, Av. PH Rolfs, s/n, Centro, CEP 36570-900, Viçosa (MG), Brasil. emanuele.pereira@ufv.br (ORCID: 0000-0002-2642-312X)

Físico, Dr., Professor do Instituto Federal do Mato Grosso, Campus Cuiabá, Rua Professora Zulmira Canavarros 95, CEP 78000-000, Cuiabá (MT), Brasil. ivanildomt@gmail.com (ORCID: 0000-0002-0303-2724)

Engenheira Florestal, Dra., Professora do Programa de Pós-Graduação em Florestal, Departamento de Engenharia Agrícola, Universidade Federal de Viçosa, Av. PH Rolfs, s/n, Centro, CEP 36570-900, Viçosa (MG), Brasil. cassiacarneiro@ufv.br (ORCID: 0000-0002-5992-3059)
\end{abstract}




\section{Introdução}

A indústria brasileira do aço foi responsável por 2,1\% da produção mundial de aço entre 2014 e 2015, totalizando 33,2 milhões de toneladas de aço bruto, subindo do 9o para o $8^{\circ}$ lugar dentre os produtores mundiais, liderado pela China com uma produção de 803,8 milhões de toneladas (INSTITUTO AÇO BRASIL, 2016).

A siderurgia sustentável brasileira demanda a produção de carvão vegetal. Em 2015, o setor siderúrgico registrou um consumo de 4,6 milhões de toneladas desse insumo energético (INDÚSTRIA BRASILEIRA DE ÁRVORES, 2016). A siderurgia utiliza o carvão vegetal como fonte de energia e agente redutor de minério de ferro em substituição ao coque de carvão mineral, principalmente na produção de ferro-gusa. Para cada tonelada de ferro produzida com carvão vegetal proveniente de florestas plantadas, há um ganho ambiental de aproximadamente três toneladas de dióxido de carbono $\left(\mathrm{CO}_{2}\right)$, em comparação ao uso de fontes fósseis ou não renováveis (INDÚSTRIA BRASILEIRA DE ÁRVORES, 2016). Adicionalmente, Silva (2007) destaca que a siderurgia a carvão vegetal libera ao meio ambiente 1,53 toneladas de $\mathrm{O}_{2}$ por tonelada de aço produzida.

O cenário de produção de carvão vegetal no Brasil ainda é precário, mas com pujante demanda por inovações que não agreguem custo ao produto. Os maiores desafios na produção nacional do carvão estão relacionados à tecnologia empregada na sua produção (PEREIRA et al., 2016) visto que a maior parcela do carvão vegetal produzido é proveniente de fornos rudimentares e com baixo nível tecnológico empregado (CARDOSO et al., 2010).

De acordo com a ABRAF (ASSOCIAÇÃO BRASILEIRA DE PRODUTORES DE FLORESTAS PLANTADAS, 2013), as empresas siderúrgicas a carvão vegetal estão aumentando a eficiência do processo de carbonização da madeira e do processo industrial com a finalidade de aprimorar a sustentabilidade do setor, e diferenciar seu produto no mercado. Nesse contexto, o resfriamento artificial é uma técnica complementar a produção de carvão vegetal que visa a redução do tempo de resfriamento do carvão que pode durar de 8 a 14 dias (OLIVEIRA et al., 2015), aumentando a capacidade produtiva e, consequentemente, a renda dos produtores. A partir disso, o presente trabalho tem por objetivo o estudo do resfriamento artificial, visando à redução do ciclo produtivo, sem alterar as propriedades físicas e químicas do carvão vegetal.

\section{Material e métodos}

O experimento foi realizado no Laboratório de Painéis e Energia da Madeira (LAPEM) do Departamento de Engenharia Florestal da Universidade Federal de Viçosa, Viçosa-MG.

Os efeitos da taxa de resfriamento no rendimento e na qualidade final do carvão foram investigados em experimento com delineamento inteiramente casualizado, com quatro velocidades de escoamento de gases pelo leito, em três repetições, totalizando doze ensaios de carbonizações. A decisão quanto ao número de repetições foi baseada em ensaios preliminares e trabalhos científicos sobre a avaliação da qualidade do carvão vegetal em função dos parâmetros da carbonização. Os dados foram submetidos à análise de variância (ANOVA) com 5\% de significância pelo teste F. Quando estabelecidas diferenças significativas, a comparação múltipla das médias obtidas foi feita ao nível de $95 \%$ de probabilidade pelo teste de Tukey.

Os ensaios de carbonização e resfriamento foram conduzidos em forno retangular com dimensões internas de 2,3 $\mathrm{m}$ de comprimento, 1,6 m de largura, 2,0 $\mathrm{m}$ de altura com 0,5 $\mathrm{m}$ de flecha na cúpula(CARDOSO et al., 2010), com capacidade para 10 estéreos $\left(7 \mathrm{~m}^{3}\right)$ de madeira (SOCIEDADE BRASILEIRA DE SILVICULTURA, 2008). A carbonização foi realizada pelo controle da admissão de ar atmosférico nas entradas, localizadas na parte inferior das laterais do forno, com monitoramento das temperaturas na cúpula e seguindo a curva teórica de degradação térmica da madeira (Figura 1), descrita por Oliveira et al. (2013), para o forno em estudo. 
Figura 1 - Curva teórica de carbonização para monitoramento de temperaturas na cúpula do forno

Figure 1 - Theoretical carbonization curve for temperature monitoring at the furnace dome

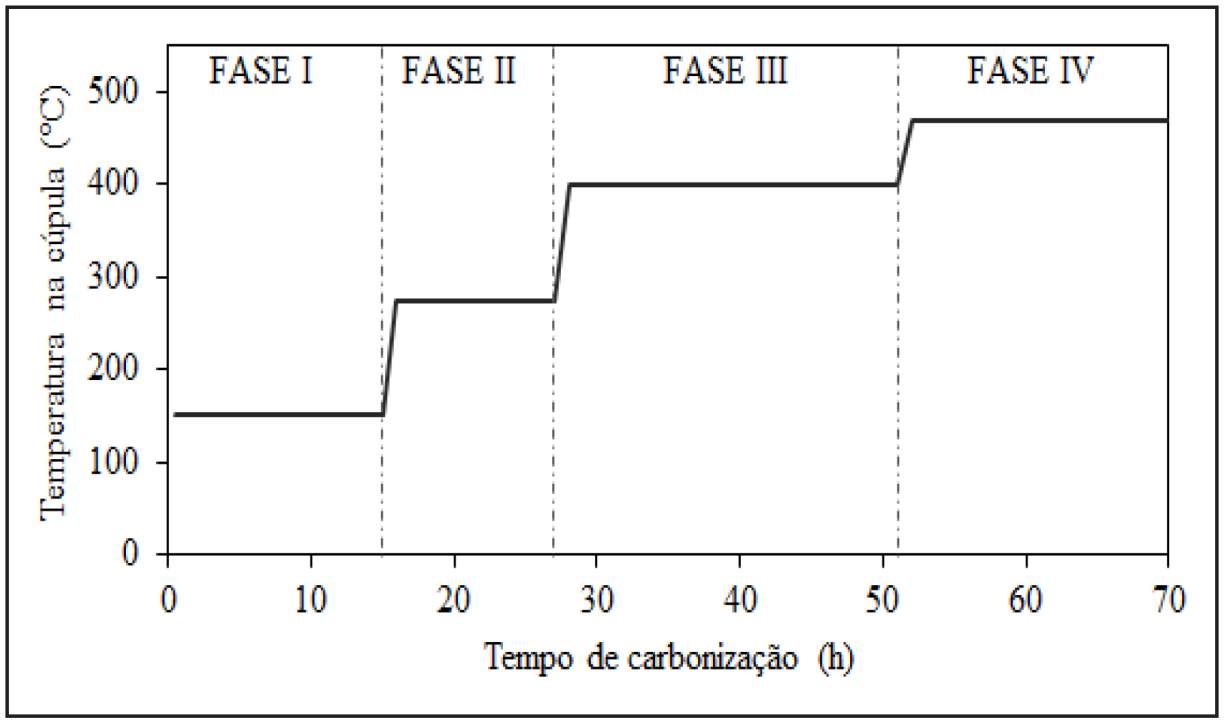

Fonte: Oliveira et al. (2013)

Figura 2 - Sistema de carbonização composto por forno (A), chaminé com queimador (B) e trocador de calor $(\mathrm{C})$. Os pontos em amarelo indicam a posição dos termopares

Figure 2 - Carbonization system composed by furnace (A), chimney with burner (B) and heat exchanger $(\mathrm{C})$.The yellow dots indicate the thermocouple positions

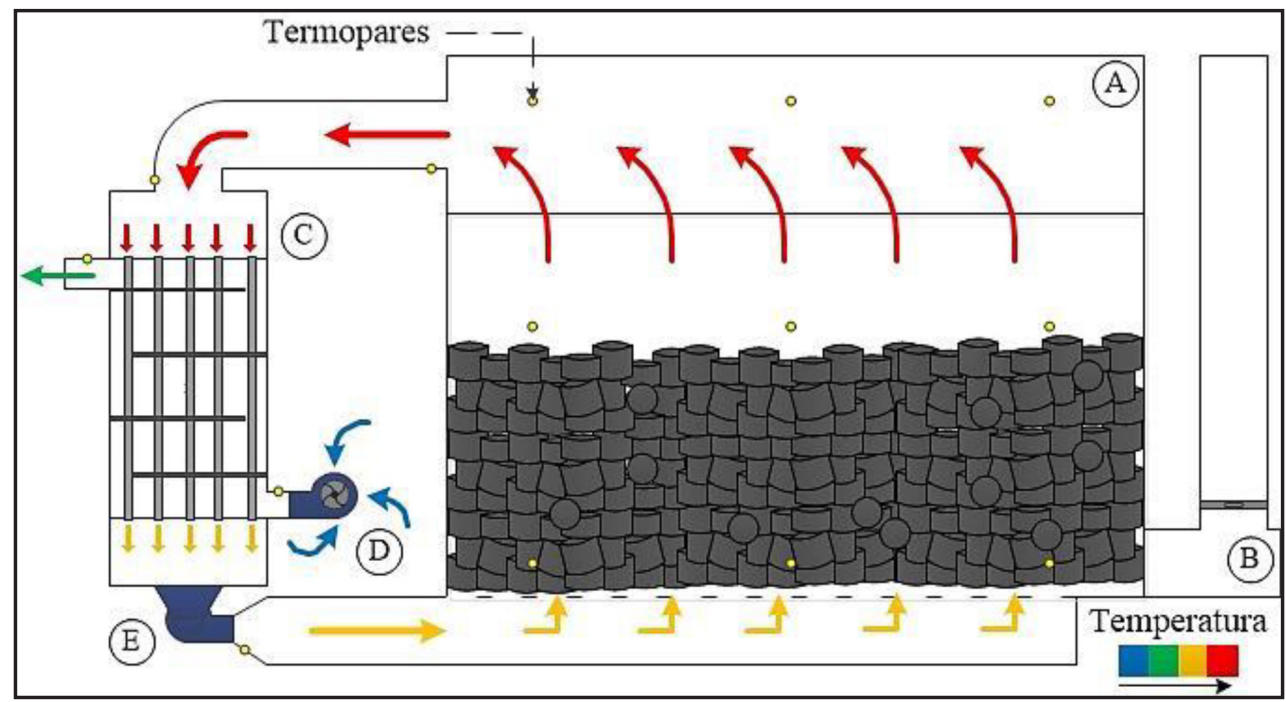

Fonte: Autores (2014) 
O trocador de calor (Figura 2) foi dimensionado e confeccionado na configuração casco e tubo, com um passe no casco, com arranjo tipo TEMA E (TUBULAR EXCHANGER MANUFACTURERS ASSOCIATION, 2007). O trocador construído possui 100 tubos aço carbono SAE 1020 com diâmetro interno de 19,05 mm, parede com espessura de $1 \mathrm{~mm}$ e 1,80 $\mathrm{m}$ de altura dispostos em arranjo triangular, com área de troca térmica de $8,98 \mathrm{~m}^{2}$. O controle de vazão foi efetuado com dois ventiladores, um para ajuste da vazão de ar que escoa sobre o feixe de tubos (Figura 2D) e outro para ajuste da vazão de recirculação dos gases de carbonização, que escoam nos tubos (Figura 2E).

Para avaliar o efeito da vazão no desempenho do resfriamento, foram empregadas quatro velocidades de escoamento de gás de carbonização pelo leito de carvão vegetal, ajustadas por uso de um inversor de frequência (CFW 10, WEG, Brasil) nos motores dos ventiladores (Figuras $2 \mathrm{D}$ e 2E). Essas velocidades foram escolhidas com bases em estudos de resfriamento artificial de carvão vegetal em fornos de alvenaria (SILVA; MARTINS, 2018). O primeiro ensaio foi realizado sem o acionamento dos ventiladores (testemunha), representando o resfriamento natural. Nos demais testes, o motor do ventilador operou com frequências de $30 \mathrm{~Hz}, 45 \mathrm{~Hz}$ e $60 \mathrm{~Hz}$, resultando em velocidades superficiais iguais a $0,034 \mathrm{~m} \mathrm{~s}^{-1}, 0,060 \mathrm{~m} \mathrm{~s}^{-1}$ e $0,108 \mathrm{~m} \mathrm{~s}^{-1}$, respectivamente. A velocidade superficial é definida pela razão entre a vazão e a área transversal do forno, e é um parâmetro utilizado para caracterizar o escoamento em meios porosos.

O sistema de aquisição de dados foi composto por 14 termopares tipo K, ligados a dois módulos seriais de aquisição de dados (LR- 7018, ICP DAS, China) e um módulo conversor bidirecional optoisolado RS-232 para RS-485 a dois fios (LR-7520, ICP DAS, China). Os termopares foram distribuídos no sistema forno/trocador de calor (Figura 2), sendo quatro para as entradas e saídas do trocador de calor, três a $0,5 \mathrm{~m}$ do piso, três a $1,5 \mathrm{~m}$ do piso, três na cúpula do forno, e um no duto que interliga a cúpula do forno ao trocador de calor.

Após a carbonização e o resfriamento, três amostras de $15 \mathrm{~kg}$ de carvão vegetal foram coletadas em posições distintas do forno: próximo à porta, no meio e ao fundo do forno. As amostras foram preparadas para os ensaios físicos e químicos conforme recomendado pela norma ABNT NBR 9165 (1985), com homogeneização e quarteamento. A densidade a granel foi obtida da razão entre a massa de uma amostra contida em uma caixa cúbica de madeira com volume interno de $0,216 \mathrm{~m}^{3}$, de acordo com a norma ABNT NBR 6922 (1981), enquanto a densidade relativa aparente foi determinada conforme os procedimentos da norma ABNT NBR 9165 (1985). O poder calorífico superior (PCS) do carvão vegetal foi determinado por meio da bomba calorimétrica adiabática (C200, IKA WORKS, China), de acordo com a norma ABNT NBR 8633 (1984). A determinação dos teores de materiais voláteis (MV), cinzas (CZ) e carbono fixo (CF) seguiram os procedimentos da norma ABNT NBR 8112 (1986). No ensaio de friabilidade, amostras de $0,5 \mathrm{~kg}$ de carvão, classificadas entre as granulometrias de $20 \mathrm{~mm}$ a $60 \mathrm{~mm}$, foram introduzidas em um tambor rotativo de aço, com $30 \mathrm{~cm}$ de diâmetro, e foram submetidas a 500 rotações a $30 \mathrm{rpm}$, segundo metodologia sugerida por Oliveira, Vivacqua Filho e Gomes (1982). A razão entre a massa de carvão com granulometria inferior a $13 \mathrm{~mm}$ após o ensaio e a massa introduzida no tambor, define o parâmetro denominado friabilidade.

O rendimento gravimétrico (OLIVEIRA, 2012) é definido pela razão entre a massa de carvão produzido e a massa seca de madeira enfornada, sendo a massa seca obtida após determinação da umidade da madeira.

$$
\mathrm{RG}=\frac{m_{c}}{m_{s}}
$$

Em que: $\mathrm{RG}=$ rendimento gravimétrico $(\%) ; \mathrm{m}_{\mathrm{c}}=$ massa de carvão vegetal produzida $(\mathrm{kg}) ; \mathrm{m}_{\mathrm{s}}=$ massa seca de madeira enfornada $(\mathrm{kg})$. 


\section{Resultado e discussão}

O forno foi preenchido com madeira de Eucalyptus sp. com 8 anos de idade. As toras foram dispostas no forno na posição vertical e apresentaram valores médios de comprimento de 2,10 m, diâmetro de 8 a $25 \mathrm{~cm}$, teor de água $33 \pm 6 \%$ b.s., poder calorífico superior de $18593,7 \mathrm{~kJ} \mathrm{~kg}^{-1} \mathrm{e}$ massa específica básica de $490 \mathrm{~kg} \mathrm{~m}^{-3}$.

Durante os ensaios de carbonização, as temperaturas internas aumentaram em função da fase pirólise, segundo a curva teórica utilizada para o controle da carbonização no forno, conforme exemplificado pelo ensaio 01 (Figura 3), com resfriamento natural posterior.

\section{Figura 3 - Perfil de temperaturas médias do forno durante a carbonização para o ensaio 01}

Figure 3 - Average temperature profiles of the furnace during the carbonization in test 01

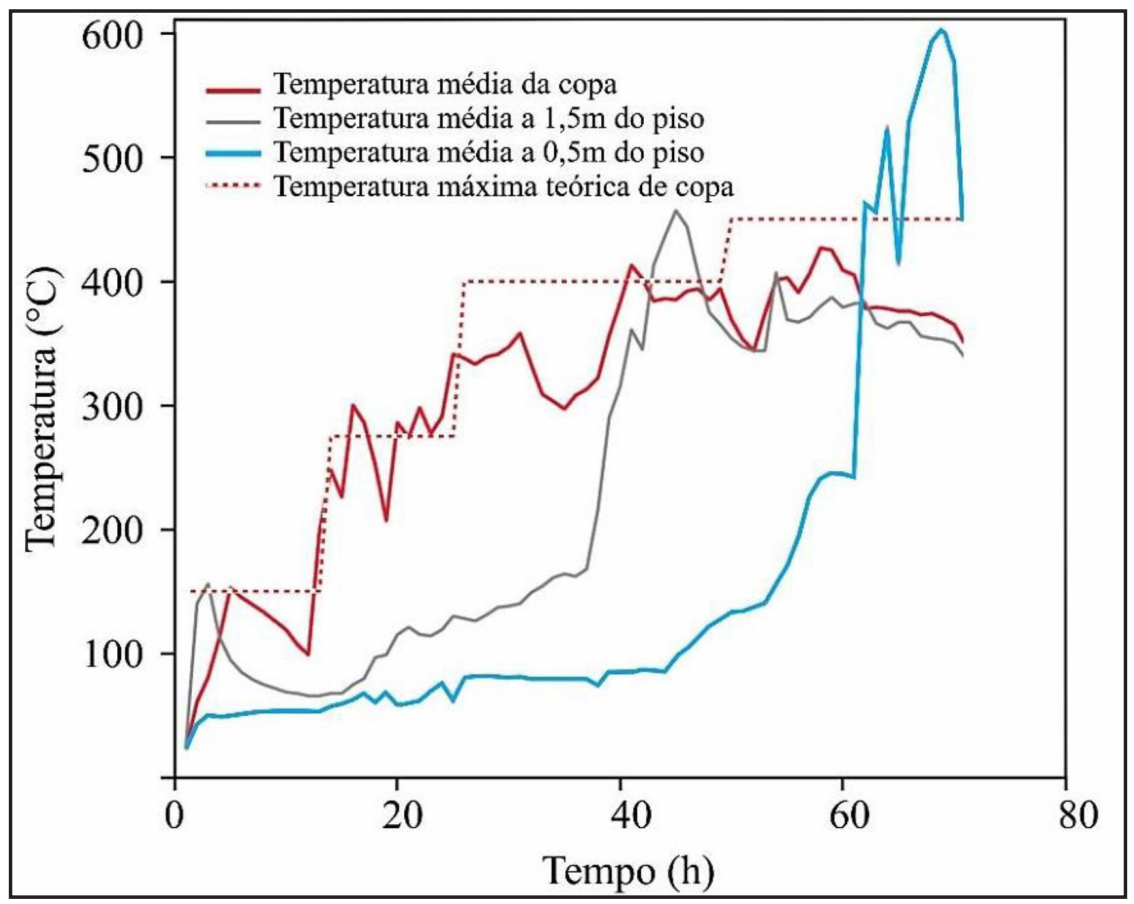

Fonte: Autores (2014)

Observa-se na Figura 3 a variação entre as temperaturas na cúpula e as temperaturas da parte inferior do forno, a 0,5 m e 1,5 m do piso. Essa variação diminuiu com a evolução da pirólise e caracteriza o deslocamento da frente de carbonização para o interior do forno. Para o forno em estudo (Figura 2), destaca-se que a frente de carbonização se inicia na parte superior do forno e se desloca na direção diagonal do forno, no sentido da porta para a chaminé. Dessa forma, o piso ao fundo do forno é a última região a ser atingida pela frente de carbonização.

O resfriamento por convecção natural (Figura 4A) teve duração de 76 horas, com menor taxa de resfriamento quando comparado ao resfriamento com trocador de calor (Figuras 4B-C), evidenciando a grande resistência térmica dos elementos estruturais do forno. Essa resistência é tanto adequada quanto desejável durante a carbonização, pois minimiza as perdas de calor e mantém a madeira a temperaturas adequadas para o processo de pirólise. No entanto, durante o resfriamento essa resistência deve ser vencida para a diminuição do ciclo do processo de carbonização, aumentando assim a produtividade das unidades de produção de carvão vegetal.

Durante a pirólise e resfriamento natural, os pontos de medida de temperatura na cúpula do forno sempre apresentaram valores maiores quando comparado ao leito de carvão. Essa 
observação experimental é justificada pelo transporte de calor por convecção natural, pois os gases mais quentes possuem massa específica menor e, portanto, escoam para a parte superior do forno. Essa observação é importante para futuras implantações de sistemas de resfriamento sem uso de motores, pois ao se conectar a cúpula do forno ao duto subterrâneo, por um trocador posicionado acima do forno, as correntes de convecção natural serão intensificadas, acelerando a marcha de resfriamento.

Figura 4 - Distribuição de temperaturas no forno durante o resfriamento, com sistema de ventilação operando nas frequências: (A) $0 \mathrm{~Hz}$ (resfriamento natural), (B) $30 \mathrm{~Hz},(\mathrm{C}) 45 \mathrm{~Hz}$ e (D) $60 \mathrm{~Hz}$

Figure 4 - Temperature distribution in the furnace during cooling, with ventilation system operating in frequencies: (A) $0 \mathrm{~Hz}$ (natural cooling), (B) $30 \mathrm{~Hz}$, (C) $45 \mathrm{~Hz}$ and (D) $60 \mathrm{~Hz}$

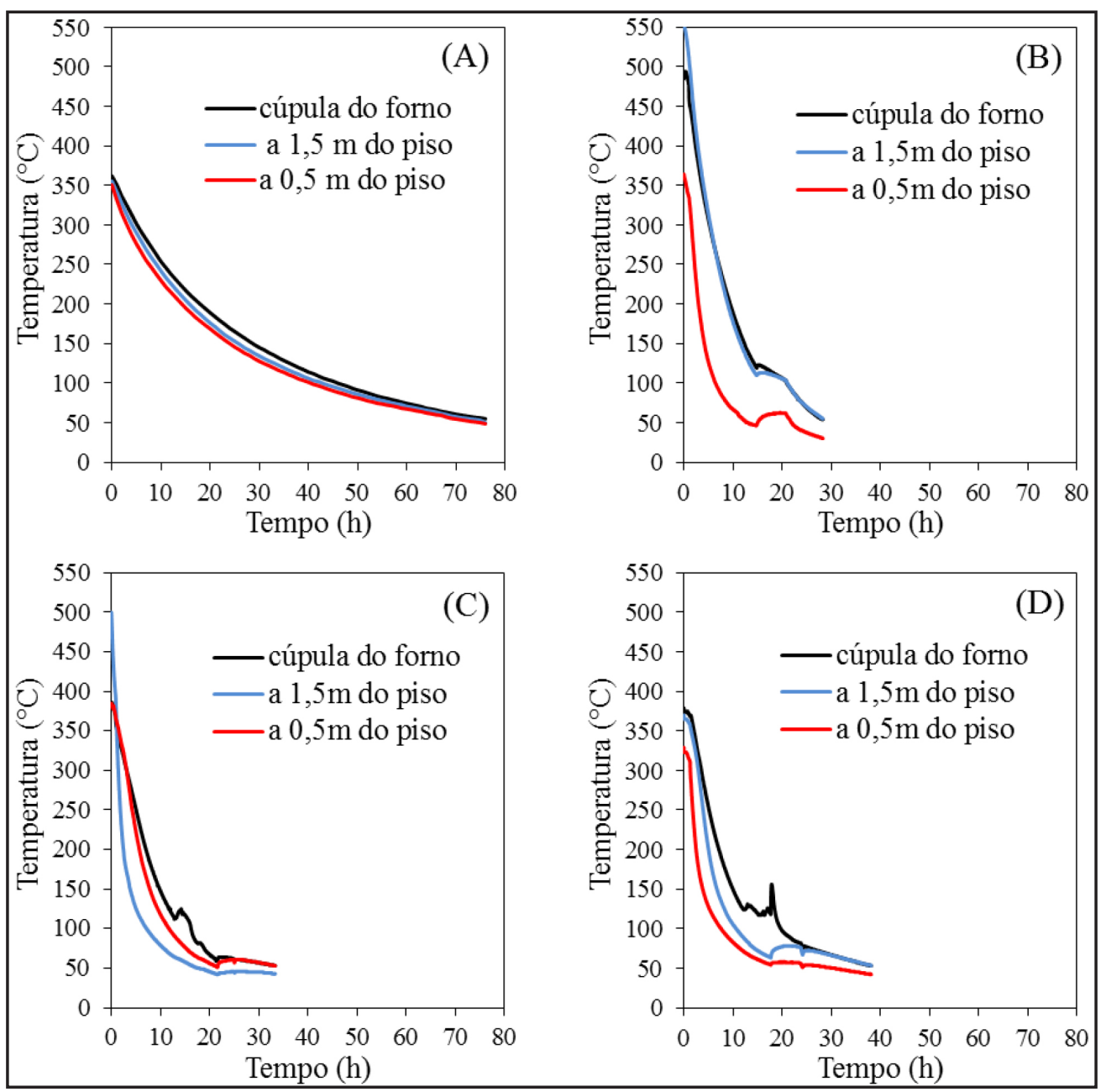

Fonte: Autores (2014)

Com o acionamento do sistema de ventilação a $30 \mathrm{~Hz}$ (Figura 4B), obteve-se velocidade superficial de resfriamento de $0,034 \mathrm{~m} \mathrm{~s}^{-1}$ e vazão de $0,124 \mathrm{~m}^{3} \mathrm{~s}^{-1}$, sendo gerada uma diferença de pressão estática entre a saída e entrada dos gases do forno igual a $139 \mathrm{~Pa}(14,2 \mathrm{mmca})$. O tempo de resfriamento com essa velocidade superficial foi de 28 horas, proporcionando redução de $63 \%$ no tempo de resfriamento em relação ao resfriamento natural.

Aumentando a velocidade superficial dos gases pela massa de carvão para $0,060 \mathrm{~m} \mathrm{~s}^{-1}$ 
(Figura 4C), com o acionamento dos motores em $45 \mathrm{~Hz}$, a diferença de pressão estática aumentou para $238 \mathrm{~Pa}(24,3 \mathrm{mmca})$. O tempo médio de resfriamento nessa configuração foi de 33 horas, proporcionando redução de $56,6 \%$ no tempo de resfriamento em relação ao resfriamento natural. Nota-se que após as 12 horas de resfriamento ocorreram oscilações na temperatura da curva de resfriamento, indicando um aquecimento do carvão no interior do forno, devido provavelmente à infiltração de ar no sistema. Ao operar o sistema de ventilação a $60 \mathrm{~Hz}$ (Figura 4D), obtevese velocidade superficial dos gases no leito de carvão igual a $0,108 \mathrm{~m} \mathrm{~s}^{-1}$. Nesse escoamento, a diferença de pressão estática entre a saída e entrada dos gases no forno foi de $353 \mathrm{~Pa}(36 \mathrm{mmca})$. O comportamento do perfil de temperaturas foi análogo ao verificado para o caso anterior (Figura 4C), com oscilações ainda mais intensas nas temperaturas da copa após as 12 horas. O tempo médio de resfriamento para essa velocidade superficial foi de 38 horas, proporcionando redução de $50 \%$ no tempo de resfriamento em relação ao resfriamento por convecção natural.

A marcha de resfriamento do forno, como observado nos gráficos da Figura 4, não apresentou redução no tempo de resfriamento para velocidades de escoamento superiores a $0,034 \mathrm{~m} \mathrm{~s}^{-1}$ (inversor a $30 \mathrm{~Hz}$ ). O acionamento dos ventiladores em maiores frequências, ou seja, com maiores velocidades superficiais do gás no leito de carvão, proporcionou maior diferença de pressão no interior do forno, provocando infiltrações de ar e, consequentemente, focos de combustão no carvão próximo a sucção dos gases. Tais indícios de queimas foram confirmados pelas oscilações na curva de temperatura característica de resfriamento, para a velocidade adotada, entre o $10^{\mathrm{a}}$ e a $25^{\mathrm{a}}$ hora de resfriamento (Figuras $4 \mathrm{~B}-\mathrm{C}$ ).

Em todos os tratamentos com resfriamento artificial, após o desligamento do sistema de ventilação, ocorreu elevação da temperatura em todos os pontos internos do forno. Esse fenômeno ocorre porque os gases quando em escoamento forçado recebem calor das paredes e da massa de carvão e em seguida perdem esse calor no trocador. Quando o escoamento é interrompido, esses gases acumulam esse calor, o que aumenta sua energia interna e resulta em aumento de temperatura.

A variação da velocidade dos gases pelo leito e consequentemente o tempo de resfriamento, não ocasionaram variação significativa no rendimento gravimétrico $(R G)$ e nas propriedades do carvão, exceto para o parâmetro friabilidade ( $\mathrm{Fr}$ ) (Tabela 1). Os resultados foram submetidos à análise de variância, ao nível de $95 \%$ de probabilidade, pelo teste $\mathrm{F}$.

Tabela 1 - Valores médios do rendimento gravimétrico e das propriedades do carvão em função das diferentes velocidades superficiais dos gases pelo leito durante o resfriamento

Table 1 - Average values of the gravimetric yield and properties of the charcoal due to the different gas flow speeds through the bed during the cooling

\begin{tabular}{|c|c|c|c|c|c|c|c|c|c|}
\hline \multirow{3}{*}{$\begin{array}{c}\text { Velocidade } \\
\text { superficial } \\
\qquad\left(\mathrm{m} \mathrm{s}^{-1}\right)\end{array}$} & \multicolumn{9}{|c|}{ Parâmetros } \\
\hline & RG & Cf & RCF & $\mathrm{Cz}$ & Fr & MV & PCS & DAP & DAG \\
\hline & (\%) & (\%) & $(\%)$ & (\%) & (\%) & $(\%)$ & $\left(\mathbf{k c a l ~ k g}^{-1}\right)$ & $\left(\mathbf{k g ~ m}^{-3}\right)$ & $\left(\mathrm{kg} \mathrm{m}^{-3}\right)$ \\
\hline 0 & 30,9 & 71,7 & 22,15 & 0,30 & $13,6^{\mathrm{ab}}$ & 28,0 & 6932 & 342 & 154 \\
\hline 0,034 & 27,1 & 79,8 & 21,62 & 0.32 & $14,6^{\mathrm{a}}$ & 19,9 & 7249 & 353 & 156 \\
\hline 0,060 & 28,2 & 81,5 & 22,98 & 0,25 & $12,0^{\mathrm{b}}$ & 18,3 & 7515 & 342 & 154 \\
\hline 0,108 & 32,0 & 73,5 & 23,52 & 0,26 & $12,1^{b}$ & 26,3 & 7201 & 341 & 158 \\
\hline
\end{tabular}

Fonte: Autores (2014)

Em que: $R G$ = rendimento gravimétrico do carvão vegetal; $R C F$ = rendimento em carbono fixo; $C f=$ teor de carbono fixo; $\mathrm{Cz}$ = teor de cinzas; $\mathrm{Fr}$ = teor de friabilidade; $\mathrm{PCS}=$ poder calorífico superior; $\mathrm{MV}$ = teor de materiais voláteis; $\mathrm{DAP}=$ densidade aparente; $\mathrm{DAG}=$ densidade a granel. Valores médios de friabilidade, seguidos de mesma letra na coluna, não diferem entre si pelo teste de Tukey, ao nível de $95 \%$ de probabilidade. 
O rendimento gravimétrico variou entre 27,1 e 32,0\% (Tabela 1). Não houve diferença estatística entre os valores obtidos, sendo a variação do rendimento gravimétrico mais dependente dos procedimentos de carbonização e variáveis inerentes a própria madeira do que do processo de resfriamento (OLIVEIRA et al., 2013; CARNEIRO et al., 2016).

$\mathrm{O}$ teor de carbono fixo, índice muito relacionado com a temperatura de carbonização, variou entre 71,7 e $81,5 \%$, valores próximos a faixa ideal para uso na siderurgia, que demanda teores de carbono fixo entre 75 e 80 \% (SANTOS, 2008; PEREIRA et al., 2013; PROTASIO et al., 2014). Pereira et al. (2012), estudando diferentes clones de eucaliptos, obtiveram teores de carbono fixo entre 72,9 e $75,1 \%$.

O rendimento em carbono fixo (RCF) que expressa a quantidade de carbono presente na madeira que ficou retido no carvão vegetal variou de 21 a $24 \%$. Os resultados encontrados são próximos aos valores reportados na literatura, que se situam na faixa de 24 a $26 \%$ em base seca (TRUGILHO et al., 2005; BOTREL et al., 2007; NEVES et al., 2011; REIS et al., 2012; PEREIRA et al., 2013). O RCF é uma variável que está diretamente relacionada com o teor de carbono fixo e com o rendimento gravimétrico, e assim, varia com as diferentes condições de carbonizações, sobretudo com a temperatura final de carbonização, que quanto maior, menor o rendimento gravimétrico em carvão vegetal e maior o teor de carbono fixo (AZEVEDO et al., 2013).

Os teores de cinzas do carvão produzido variaram de 0,25 a $0,32 \%$, comprovando o baixo percentual de compostos inorgânicos presentes no carvão vegetal de madeira de eucalipto, em geral abaixo de 1\% (BARCELOS et al., 2005). As cinzas podem afetar as propriedades mecânicas do ferro gusa, aumentar a corrosão dos equipamentos e diminuir o poder calorífico do combustível (PEREIRA et al., 2013; PROTASIO et al., 2014).

Apesar de ocorrerem diferenças significativas para a friabilidade, ao nível de $5 \%$ de probabilidade, observa-se que os carvões vegetais resfriados artificialmente com diferentes velocidades superficiais pela massa de carvão, foram considerados pouco friáveis, segundo classificação do Centro Tecnológico de Minas Gerais (CETEC) (OLIVEIRA; VIVACQUA FILHO; GOMES, 1982; OLIVEIRA, 2012). Essa classificação evidencia que os tratamentos, de modo geral, não afetaram a resistência do carvão vegetal. Os valores de friabilidade foram ainda inferiores aos encontrados por Oliveira (2012), que variaram de 16,3 a 18,9\%. Como efeito da velocidade superficial, tem-se a taxa de resfriamento, ou seja, a variação da temperatura do carvão em função do tempo. Sugere-se que o parâmetro friabilidade seja interessantemente afetado pela taxa de resfriamento. Assim, a escolha da vazão de resfriamento deve ser norteada pelas taxas de resfriamento que não comprometam a qualidade do carvão.

Os valores de poder calorífico superior (PCS) variaram de 6932 a $7515 \mathrm{kcal} \mathrm{kg}^{-1}$, sendo o poder calorífico do carvão diretamente correlacionado ao teor de carbono fixo e inversamente correlacionado aos teores de materiais voláteis e de cinzas (DU; CHEN; LUCAS, 2014). Assim, os baixos valores de PCS também coincidiram com os testes em que as temperaturas de carbonização foram menores, todavia, os valores aproximaram dos observados por Protásio et al. (2013), cujo valor médio reportado foi de $7374 \mathrm{kcal} \mathrm{kg}^{-1}$.

Os teores de materiais voláteis (MV) correspondem a uma quantidade de compostos existentes no carvão que volatilizarão ao atingir determinadas temperaturas. Esses valores possuem relação inversa com a temperatura final de carbonização, ou seja, quanto maior a temperatura menor será o teor de materiais voláteis. Os teores de materiais voláteis variaram de 18,3 a 28,0\%, sendo a faixa ideal para a siderurgia entre 20 e 25\% (PEREIRA et al., 2013), Pereira et al. (2012) observaram valores de MV entre 24,2 e 26,7\%. Na siderurgia, matérias voláteis reduzem a eficiência do carvão no alto-forno, uma vez que maior concentração de matéria volátil significa menores níveis de carbono fixo (SANTOS, 2008).

Os valores de densidade aparente variaram de 341 a $353 \mathrm{~kg} \mathrm{~m}^{-3}$, situando-se abaixo do valor indicado por Santos (2008), que menciona valores acima de $400 \mathrm{~kg} \mathrm{~m}^{-3}$ em uma condição de temperatura final de carbonização de $550^{\circ} \mathrm{C}$, no entanto se encontra dentro da faixa observada por Botrel et al. (2007), que reportaram valores de DAP entre 280 e $400 \mathrm{~kg} \mathrm{~m}^{-3} \mathrm{em}$ experimentos 
com temperatura máxima de $450{ }^{\circ} \mathrm{C}$, permanecendo estabilizada por um período de 30 min. Esse parâmetro está relacionado com a densidade da madeira utilizada, que foi de $490 \mathrm{~kg} \mathrm{~m}^{-3}$. Madeiras com alta densidade básica irão produzir um carvão também de alta densidade (ROCHA et al., 2017).

A densidade a granel variou entre 154 e $158 \mathrm{~kg} \mathrm{~m}^{-3}$, valores considerados baixos se comparados ao valor encontrado por Santos (2008), que menciona $200 \mathrm{~kg} \mathrm{~m}^{-3}$, e ao valor observado por Oliveira (2012), de $181 \mathrm{~kg} \mathrm{~m}^{-3}$, que registrou uma temperatura máxima de $476^{\circ} \mathrm{C}$ medida na cúpula do forno. Por ter relação direta com a densidade aparente, esses resultados também estão relacionados com a baixa densidade da madeira utilizada neste experimento $\left(490 \mathrm{~kg} \mathrm{~m}^{-3}\right)$. O aumento da densidade do carvão é vantajoso ao ponto que maximiza a densidade energética do carvão e aumenta a resistência da carga no alto-forno (NEVES et al., 2011).

\section{Conclusões}

A maior eficiência obtida nos ensaios de resfriamentos foi verificada quando menores velocidades de escoamento dos gases pelo leito de carvão foram utilizadas. A vazão ideal é um fator importante a ser considerado no dimensionamento de sistemas de resfriamento com trocador de calor. O aumento das velocidades de escoamento, objetivando a redução no tempo de resfriamento, deve ser acompanhado de metodologias que minimizem a diferença de pressão entre a sucção e injeção dos gases do forno.

O uso de trocadores de calor para resfriamento do carvão em fornos de alvenaria, com escoamento forçado pela massa de carvão, não deve proporcionar grande diferença de pressão entre a sucção e injeção. Quanto maior a queda de pressão, maiores as infiltrações de ar atmosférico pelas estruturas do forno.

A variação da velocidade superficial pela massa de carvão durante os resfriamentos, não resultou em alteração significativa dos parâmetros de qualidade do carvão, exceto para a friabilidade. Mesmo assim, os valores de friabilidade obtidos classificam o carvão como pouco friável. A metodologia de resfriamento utilizada não influencia a qualidade do carvão, se comparada aos procedimentos de carbonização e à qualidade da madeira a ser carbonizada.

A circulação de gases através da massa de carvão proporcionou redução no tempo de resfriamento de 76 para 28 horas, que representa uma redução de $63 \%$ em relação ao tempo de resfriamento por convecção natural. O uso da tecnologia de resfriamento desenvolvida pode proporcionar ganhos expressivos na produtividade de carvão, pois proporciona redução no ciclo de produção.

\section{Referências}

ASSOCIAÇÃO BRASILEIRA DE NORMAS TÉCNICAS. NBR 6922: Carvão vegetal - Ensaios físicos - Determinação da massa específica - Densidade a granel. Rio de Janeiro, 1981.

ASSOCIAÇÃO BRASILEIRA DE NORMAS TÉCNICAS. NBR 8633: Carvão vegetal: Determinação do poder calorífico. Rio de Janeiro, 1984.

ASSOCIAÇÃO BRASILEIRA DE NORMAS TÉCNICAS. NBR 9165: Carvão vegetal: Determinação da densidade relativa aparente, relativa verdadeira e porosidade - Método de ensaio. Rio de Janeiro, 1985. 8 p.

ASSOCIAÇÃO BRASILEIRA DE NORMAS TÉCNICAS. NBR 8112: Carvão vegetal: análise imediata. Rio de Janeiro, 1986. 8 p.

ASSOCIAÇÃO BRASILEIRA DE PRODUTORES DE FLORESTAS PLANTADAS. Anuário estatístico da ABRAF: ano base 2012. Brasília, 2013. Disponível em: http://www.ipef.br/ estatisticas/relatorios/anuario-ABRAF13-BR.pdf. Acesso em: 26 maio 2016. 
AZEVEDO, C. H. S. et al. Influência da temperatura final de carbonização e da taxa de aquecimento no rendimento gravimétrico e teor de cinzas do carvão de Eucalyptus urophylla x Eucalyptus grandis. Enciclopédia Biosfera, Goiânia, v. 9, n. 16, p. 1279-1287, 2013.

BARCELLOS, D. C. et al. O estado da arte da qualidade da madeira de eucalipto para produção de energia: um enfoque nos tratamentos silviculturais. Biomassa \& Energia, Viçosa, MG, v. 2, n. 2, p. 141-158, 2005.

BOTREL, M. C. G. et al. Melhoramento genético das propriedades do carvão vegetal de Eucalyptus. Revista Árvore, Viçosa, MG, v. 31, n. 3, p. 391-398, 2007.

CARDOSO, M. T. et al. Construção de um sistema de queima de gases da carbonização para redução da emissão de poluentes. Cerne, Lavras, v. 16, supl., p. 115-127, jul. 2010.

CARNEIRO, A. C. O. et al. Efeito do material genético e do sítio na qualidade do carvão vegetal de madeira de curta rotação. Floresta, Curitiba, v. 46, n. 4, p. 473-480, 2016.

DU, S.; CHEN, W.; LUCAS, J. A. Pretreatment of biomass by torrefaction and carbonization for coal blend used in pulverized coal injection. Bioresource Technology, [s. l.], v. 161, p. 333-339, 2014.

INDÚSTRIA BRASILEIRA DE ÁRVORES. Relatório Estatístico 2015. São Paulo, 2016. Disponível em: http://iba.org/images/shared/Biblioteca/IBA_RelatorioAnual2016_pdf. Acesso em: 26 maio 2016.

INSTITUTO AÇO BRASIL. Relatório de Sustentabilidade 2016 - dados 2014/2015. Rio de Janeiro, 2016. Disponível em: http://www.acobrasil.org.br/sustentabilidade/. Acesso em: 26 mai. 2016.

NEVES, T. A. et al. Avaliação de clones Eucalyptus em diferentes locais visando à produção de carvão vegetal. Pesquisa Florestal Brasileira, Colombo, v. 31, n. 68, p. 319-330, 2011.

OLIVEIRA, A. C. Sistema forno-fornalha para produção de carvão vegetal. 2012. Dissertação (Mestrado) - Universidade Federal de Viçosa, Viçosa, MG, 2012.

OLIVEIRA, A. C. et al. Otimização da produção do carvão vegetal por meio do controle de temperaturas de carbonização. Revista Árvore, Viçosa, MG, v. 37, n. 3, p. 557-566, 2013.

OLIVEIRA, A. C. et al. Resfriamento artificial em fornos retangulares para a produção de carvão vegetal. Revista Árvore, Viçosa, MG, v. 39, n. 4, p. 769-778, 2015.

OLIVEIRA, J. B; VIVACQUA FILHO, A.; GOMES, P. A. Produção de Carvão Vegetal - aspectos técnicos. In: PRODUÇÃO e utilização de carvão vegetal. Belo Horizonte: Fundação Centro Tecnológico de Minas Gerais, 1982. p. 60-73.

PEREIRA, B. L. C. et al. Influence of chemical composition of Eucalyptus wood on gravimetric yield and charcoal properties. BioResources, [s. l.], v. 8, p. 4574-4592, 2013.

PEREIRA, B. L. C. et al. Quality of wood and charcoal from Eucalyptus clones for ironmaster use. International Journal of Forestry Research, [s. l.], v. 2012, p. 8, 2012.

PEREIRA, E. G. et al. Pyrolysis gases burners: sustainability for integrated production of charcoal, heat and electricity. Renewable and Sustainable Energy Reviews, [s. l.], v. 75, p. 592-600, Aug. 2016.

PROTÁSIO, T. de P. et al. Potencial siderúrgico e energético do carvão vegetal de clones de Eucalyptus spp. aos 42 meses de idade. Pesquisa Florestal Brasileira, Colombo, v. 33, n. 74, p. 137-149, 2013.

PROTÁSIO, T. de P. et al. Qualidade e avaliação energética do carvão vegetal dos resíduos do coco babaçu para uso siderúrgico. Ciência e Agrotecnologia, Lavras, v. 38, n. 5, p. 435-444, 2014. 
REIS, A. A. et al. Efeito de local e espaçamento na qualidade do carvão vegetal de um clone de Eucalyptus urophylla S. T. Blake. Floresta e Ambiente, Seropédica, v. 19, n. 4, p. 497-505, 2012.

ROCHA, M. F. V. et al. Propriedades energéticas do carvão vegetal em função do espaçamento de plantio. Brazilian Journal of Wood Science, [s. l.], v. 8, n. 2, p. 54-63, 2017.

SANTOS, M. A. S. Parâmetros de qualidade do carvão vegetal para uso em alto-forno. In: FÓRUM NACIONAL SOBRE CARVÃO VEGETAL, 1., 2008, Belo Horizonte. Anais [...]. Belo Horizonte: UFMG, 2008.

SOCIEDADE BRASILEIRA DE SILVICULTURA. Fatos e números do Brasil Florestal. São Paulo, 2008. Disponível em: http://www.sbs.org.br/FatoseNumerosdoBrasil Florestal.pdf. Acesso em: 26 maio 2016.

SILVA, G. F. B. L. Siderurgia e meio ambiente. In: INTRODUÇÃO à siderurgia. São Paulo: ABM, 2007. p. 359-400.

SILVA, I. S.; MARTINS, M. A. Resfriamento artificial de carvão vegetal em fornos de alvenaria. In: UNIVERSIDADE FEDERAL DE VIÇOSA. Sociedade de Investigações Florestais. Laboratório de Painéis e Energia da Madeira (org.). Coletânea de trabalhos científicos do grupo G6. 1. ed. Viçosa, MG: Editora UFV, 2018. v. 1. p. 156-157.

TUBULAR EXCHANGER MANUFACTURERS ASSOCIATION. Standards of the tubular exchanger manufacturers association. 9th. ed. New York, 2007.

TRUGILHO, P. F. et al. Rendimentos e características do carvão vegetal em função da posição radial de amostragem em clones de Eucalyptus. Cerne, Lavras, v. 11, n. 2, p. 178-186, 2005. 